\title{
Educação, cinema e alteridade
}

\section{Education, cinema and otherness}

\author{
Nilson Fernandes Dinis*
}

\begin{abstract}
RESUMO
Provocado pelas análises do filósofo Gilles Deleuze sobre as imagens no cinema, esse artigo propõe pensarmos as relações entre o cinema e a educação na passagem de uma pedagogia da imagem ação para uma pedagogia da imagem tempo. Essa transformação nos convida a inventar na modernidade novas formas de subjetivação e de semiotização que possam expressar a relação do sujeito consigo mesmo e com o outro, pensando o cinema como um aliado da educação no exercício de alteridade que prepara o sujeito para as infinitas travessias que o levam em direção ao outro.

Palavras-chave: cinema, mídia, educação midiática, pedagogia da imagem, alteridade.
\end{abstract}

\begin{abstract}
This article intends to make us think about the relationship between cinema and education in the change of a pedagogy of action image to a pedagogy of time image, moved by the analysis of the philosopher Gilles Deleuze about the images on the movies. This transformation invites us to invent new forms of subjectivation and new semiotics that can reveal the relationship of the subject with himself and the other persons. In this way, the cinema can be seen as another instrument to provide educational improvement in the exercise to prepare the subject for the infinite ways that take him in the other people's direction.

Key-words: cinema, media, media education, pedagogy of image, otherness.
\end{abstract}

* Professor adjunto no Departamento de Teoria e Fundamentos da Educação e no Programa de Pós-Graduação em Educação da Universidade Federal do Paraná. E.mail: nfdinis@hotmail.com 
Nas piores condições comerciais, ainda se podem produzir bons filmes, filmes que modifiquem as combinações de desejo, que destruam os estereótipos, que nos abram o futuro... (GUATTARI, 1980, p. 117)

Entre as diferenças da educação tradicional e as exigências de uma nova educação do olhar na modernidade está a necessidade de análise de outros mecanismos externos à instituição escolar como os recursos midiáticos que, no entanto, funcionam como dispositivos pedagógicos na modernidade devido às alterações nas nossas relações com o espaço, o tempo e a transmissão de informações. Imagens e sons são os signos dos recursos midiáticos e, para os efeitos deste artigo, analisaremos as imagens e sons do cinema. Mas não podemos deixar de ressaltar o impacto das imagens e sons do cinema quando comparados a um outro elemento de comunicação de massa como a televisão, e a dívida das novas gerações para com esse veículo que produz grande parte de sua educação visual, concorrendo e disputando com outras instituições tradicionais como a escola, o processo de formação. Como ressalta Almeida (2001, p. 30):

Para o espectador educado pela televisão, que vai ao cinema, (...) ele não espera ali algo para refletir, não suporta seqüências lentas - os episódios precisam suceder rapidamente uns aos outros. Esse tipo de público quer cenas agitadas, muito som, o bem e o mal nitidamente separados e em conflitos simplificados, muita violência e pouco espaço para a ternura e a bondade, que, quando aparecem, surgem como prêmio ou recompensa ao conformismo social e político.

A situação de penumbra, a amplitude da tela e do som, o silêncio e a proximidade com corpos estranhos, todos esses elementos reunidos produzem uma situação de desterritorialização, de estranhamento, um campo propício ao exercício disruptor do pensamento, diferente da convivência muda, pacífica e cristalizada da família que assenta os mesmos lugares na frente da tela da TV durante a novela das oito, compartilhando formas padronizadas de identidade.

O espaço do cinema torna-se um espaço de irrupção do diferente, um campo de imanência para o exercício do pensamento e da alteridade. E nisso reside a força mesmo do cinema comercial. Se fizermos uma rápida análise da sociedade americana, podemos observar no contexto social atual uma cer- 
ta paranóia em relação ao outro, ao diferente, às forças que produzem miscigenação e descristalização das referências identitárias. No entanto, esse cenário contrasta, mesmo nos filmes americanos mais comerciais, com um desejo recalcado de ir ao encontro da alteridade, como se o medo paranóico em relação ao outro escondesse também um enorme desejo de se desmanchar na relação com o outro, um desejo de diferenças que possam afetar e transformar a rotina de nossas vidas. Podemos citar uma infinidade de filmes comerciais: do ET a Matrix, Nell, Simples como amar, Don Juan de Marco, Chocolate, A espera de um milagre, Melhor Impossivel etc... Todos tematizam a transformação de personagens no encontro com o diferente: o alienígena, a criança excepcional, o louco, o mendigo, o negro, o forasteiro, o homossexual etc. Em Don Juan de Marco podemos mesmo dizer que o feitiço vira contra o feiticeiro: o psiquiatra corretor de comportamentos, brilhantemente interpretado pelo ator Marlon Brando, cuja função no filme é calar as intensidades do desejo que se expressam no delírio de seu paciente que acredita ser o experiente amante Don Juan, vai sofrendo mudanças em seu comportamento cristalizado e aprendendo, com seu paciente, a degustar os infinitos prazeres da vida de forma a reaquecer a insípida e fria relação que tinha com sua cônjuge. Desta forma, é no encontro com a loucura do outro que a vida cristalizada do psiquiatra descobre novas formas de reinventar a vida.

Mas um dos grandes equívocos em relação à educação e ao cinema é acreditar na função comunicativa destes veículos. A função da educação e do cinema não é informar, nem comunicar. Como nos ensina o filósofo Gilles Deleuze, comunicar é transmitir palavras de ordem, comunicar supõe sempre a presença de um sujeito emissor, de um sujeito receptor e de um código comum de linguagem. Com estes pressupostos é impossível sairmos de uma cadeia discursiva que nos obriga a dizer sempre o mesmo, comunicar é repetir o mesmo. No entanto, o cinema e a educação devem nos conduzir a um exercício de alteridade que jamais é a repetição do mesmo. É nesse sentido que é preciso corrigir um segundo equívoco: pensar o cinema como um instrumento didático que possa ilustrar os conteúdos pedagógicos. Se o cinema pode ser um interessante aliado da educação, não é porque possa ilustrá-la, traduzir didaticamente em imagens e sons os conteúdos formativos da cultura letrada. O cinema e a educação talvez possam fazer alianças pela capacidade de cada um desses campos afetar o outro, não ilustrando, o que seria a repetição do mesmo, mas porque o cinema pode conduzir a educação a novos lugares, a pensar o diferente, pode afetar produzindo um estado de ruído, de estranhamento na função comunicativa da educação de modo a levá-la a novos devires, à emergência de um novo tempo. 
Na imagem clássica da educação, essa exerce uma pedagogia de pensamento que parte do pressuposto de uma afinidade entre o pensamento e a verdade e da idéia de que a busca da verdade é uma inclinação natural do sujeito que busca e ama a verdade. Uma importante contribuição trazida por Deleuze é justamente a desconstrução desta afinidade natural entre o pensamento e a verdade. Deleuze duvida das boas intenções do sujeito que busca naturalmente a verdade. Para ele o pensamento não nasce sem algo que o force a pensar, algo que violente o sujeito e o force a pensar. O pensamento que não pensa por violência está preso apenas à recognição do mundo externo. Mas Deleuze quer mais, quer que o pensamento pense o impensável. O pensamento só funciona em relação com uma força que o faça pensar, força essa que não tem nada a ver com a força de vontade do sujeito em conhecer. As forças não vêm de dentro de um sujeito cognoscente, as forças vêm do de fora do sujeito, do de fora do próprio pensamento. Há algo fora do pensamento, fora da capacidade de recognição do mundo, que força o pensamento a pensar. O pensamento busca um mundo diferente do mundo das significações já dadas. Ora, as forças que se encontram com o pensamento são as forças do caos, forças não formadas, forças virtuais ainda informes. O pensamento tem uma afinidade com o caos. E é o contato com o caos, ou seja, as diferentes formas de entrar em contato com o caos, que vão peculiarizar as diferentes formas de pensar, que para Deleuze, se constituem seja no exercício da filosofia, seja na pedagogia, seja no exercício da artes: "Pensar é pensar por conceitos, ou então por funções, ou ainda por sensações, e um desses pensamentos não é melhor que o outro, ou mais plenamente, mais completamente, mais sinteticamente pensado" (DELEUZE; GUATTARI, 1992, p. 254).

O caos não é algo perigoso ou negativo na filosofia de Deleuze. É claro que é preciso certa prudência na nossa relação com o caos para não nos dissolvermos completamente no encontro com uma linha absoluta de morte, mas o caos é também como diz Félix Guattari, o parceiro filosófico de Deleuze, "o portador virtual de uma complexificação infinita" (GUATTARI, 1992, p.78). O caos tem uma potência em desmanchar formas pré-estabelecidas, em fazer ruir o lugar comum do mundo e da linguagem. Ele é a fonte na qual mergulha o pensamento, seja por meio da filosofia, da arte ou da ciência na busca do diferente, da força de um novo sempre inusitado. É nessa potencialidade em desmanchar as formas que a filosofia, a pedagogia e a arte irão operar, porém com procedimentos totalmente diferentes, mas sempre tentando extrair do caos um mínimo de consistência. A filosofia traça sobre o caos um plano de imanência do qual extrai seus conceitos, a ciência traça sobre o caos um plano de referência do qual extrai funções ou preposições e a arte traça sobre o 
caos um plano de composição, dos quais quer extrair as sensações, ou seja perceptos e afectos puros.

$\mathrm{O}$ que define o pensamento, as três grandes formas do pensamento, a arte, a ciência e a filosofia é sempre enfrentar o caos, traçar um plano, esboçar um plano sobre o caos. Mas a filosofia quer salvar o infinito, dando-lhe consistência: ela traça um plano de imanência que leva até o infinito acontecimentos ou conceitos consistentes sob a ação dos personagens conceituais. A ciência, ao contrário, renuncia ao infinito para ganhar a referência: ela traça um plano de coordenadas somente indefinidas que define sempre estados de coisas, funções ou proposições referenciais, sob a ação de observadores parciais. A arte quer criar um finito que restitua o infinito: traça um plano de composição que carrega por sua vez monumentos ou sensações compostas sob a ação das figuras estéticas (DELEUZE; GUATTARI, 1992, p. 253).

Poderíamos dizer com Deleuze que a pedagogia, em sua afinidade com a filosofia, também é a arte de formar, de inventar, de fabricar conceitos. Mas quando colocamos que a filosofia ou a pedagogia dá uma consistência ao caos, por meio da criação do conceito, isso não quer dizer necessariamente que a filosofia imponha uma forma ao caos. A menos que possamos pensar paradoxalmente em uma forma sem limite, uma forma disforme, um contorno irregular, uma totalidade fragmentária. A consistência implica na coexistência virtual de séries divergentes, dos elementos mais heterogêneos. A consistência está em relação com um plano de consistência ou plano de imanência que se opõe ao plano de organização onde estão as formas. Um não pára de desmanchar o outro e os dois apenas se relacionam em um perpétuo movimento de territorialização e desterritorialização.

Não queremos esgotar por meio desse esboço a importância dos conceitos produzidos pela parceria filosófica de Gilles Deleuze e Félix Guattari, uma obra cujo resultado são textos instigantes como Lógica do Sentido, Diferença e Repetição, Mil Platôs, O que é filosofia ou ainda suas análises sobre o cinema presentes em Cinema: a imagem-movimento e Cinema: a imagemtempo. Apenas provocados pelos conceitos destes autores, buscamos outras articulações entre o cinema e a educação que se desviam de uma função comunicativa ou informativa destes veículos. A educação e o cinema são formas de exercitar o pensamento. No entanto, é preciso lutar contra o senso 
comum e o bom senso para que a função da educação e da arte seja a invenção de novas realidades, e não a repetição do mesmo. Assim o exercício do pensamento já não pode ser apenas um ato de recognição. O pensamento deve pensar o impensável. Ou seja ver o que não se vê, ouvir o que não se ouve, sentir o que não se sente. Levar cada sensação além do limite da sua própria capacidade. Esse novo pensamento já não pressupõe estruturas preexistentes, cria suas próprias possibilidades, seus próprios objetos a pensar e sua própria forma cada vez que ganha a expressão. Ele é um universo em perpétua expansão. É um pensamento experimental e não um pensamento analítico. Seu objetivo nunca é descobrir ou resgatar o real, mas a todo momento produzi-lo. Um pensamento que jamais se repete, um pensamento que só se constrói quando produz suas próprias variações e o seu próprio tempo.

Como nos aponta Deleuze, nos condicionamos a pensar o tempo como subordinado ao movimento. É o que está implícito no senso comum quando nos perguntamos, por exemplo, quanto tempo leva entre duas localidades. Estamos articulando a idéia de tempo com o movimento do automóvel, do trem, do avião que serve de transporte para percorrermos o percurso entre as duas localidades. Portanto, o tempo seria o resultado do movimento. Acabado o movimento, acabaria o tempo. Essa é também a idéia que temos do tempo no cinema, já que o tempo no cinema é necessariamente um artifício porque resulta da montagem que liga uma imagem-movimento a outra. Estamos também todos presos a uma imagem do tempo cronometrado do relógio que é uma idealização do tempo em torno do movimento perfeito que é o movimento circular, o movimento que um corpo realiza em torno de si próprio. Assim estamos presos à idéia de que um acontecimento pressupõe o eterno retorno de uma seqüência que envolve começo, meio e fim.

No entanto, ao analisar a história do cinema, Deleuze observa que na década de 40, no pós-guerra, surgem nas imagens do cinema tentativas de romper com essa imagem do tempo subordinada ao movimento, por meio da nouvelle vague francesa, do neo-realismo italiano e mesmo no cinema americano com os filmes de Orson Welles.

De repente as situações já não se prolongam em ação ou reação como exigia a imagem movimento. São puras situações óticas e sonoras, nas quais a personagem não sabe como responder, espaços desativados nos quais ela deixa de sentir e agir, para partir para a fuga, a perambulação, o vaivém, vagamente indiferente ao que lhe acontece, indecisa sobre o que é preciso fazer. Mas ela ganha em vidência o que perde em ação ou 
reação: ela VÊ, tanto assim que o problema do espectador torna-se "o que há para ser visto na imagem?" ( e não mais "o que veremos na próxima imagem?”). A situação já não mais se prolonga em ação por intermédio das afecções. Está cortada de todos os seus prolongamentos, só vale por si mesma, tendo absorvido todas as suas intensidades afetivas, todas as suas extensões ativas. Já não é uma situação sensório-motora, mas uma situação puramente ótica e sonora, na qual o vidente substitui o actante: uma "descrição". Chamamos de opsignos e sonsignos o tipo de imagem que ocorre após a guerra, por todas as razões anteriores que se possa designar (questionamento da ação, necessidade de ver e ouvir, proliferação dos espaços vazios, desconectados, desativados), mas também devido à impulsão interior de um cinema renascente, recriando suas condições, neo-realismo, nouvelle vague, novo cinema americano. Ora, se é verdade que a situação sensório-motora impunha a representação indireta do tempo como conseqüência da imagem-movimento, a situação puramente ótica ou sonora abre-se com base numa imagem-tempo direta. A imagem-tempo é o correlato do sonsigno e do opsigno (...) Em vez da "situação motora -representação indireta do tempo", temos o "opsigno ou sonsigno-apresentação direta do tempo" (DELEUZE, 1990, p. 323-324).

A passagem da imagem movimento a uma imagem tempo implica em uma outra relação com o real: no cinema já não se trata mais de representar ou reproduzir um real já pronto, mas produzir novas realidades, novos mundos possíveis nos quais o tempo já não esteja subordinado ao movimento, ou mesmo a uma seqüência irreversível de passado-presente-futuro. Trata-se da emergência de situações ópticas e sonoras substituindo situações sensóriomotoras enfraquecidas. São produzidas situações de visibilidade e audição que não derivam de ações, nem necessariamente se prolongam em ações. Elas desconstroem a antiga imagem-ação, rompendo a ligação sensório-motora com intervalos que fazem emergir situações ópticas e sonoras puras, elementos que compõem a imagem tempo. Em vez de uma representação direta do tempo, operação da montagem do filme, temos agora uma "promoção do movimento aberrante" no qual o tempo se liberta do movimento. Ou podemos dizer ainda que se antes o movimento recebia sua regra de um esquema sensório-motor, apresentando, por exemplo, a história linear de uma personagem que reagia a uma determinada situação, com o advento da imagem tempo o esquema sensório-motor se desmorona em favor de movimentos não orientados, desconexos, levando as personagens a viverem não mais uma história linear, mas devires, acontecimentos disruptores que transbordam uma apreensão linear ou causalista do tempo. 
Um dos mais claros exemplos de imagem-tempo é o roteiro elaborado pela escritora francesa Marguerite Duras para o filme Hiroshima, mon amour, de Alain Resnais. Aliás tanto a escritora como o cineasta são citados inúmeras vezes no livro de Deleuze sobre a imagem-tempo. Há no filme uma disjunção entre o visual e o sonoro que, no entanto, são conectados em uma espécie de relação não totalizável, uma integração irracional e incomensurável entre o visual e o sonoro. No filme de Resnais vemos alguma coisa e a fala nos diz de outra coisa. Distância entre o ver e o falar, entre o visível e o dizível, entre as palavras e as coisas. O narrador viu tudo, o narrador viu nada. Inventou tudo, mas também pode não ter inventado nada. A imagem que abre o filme com os corpos entrelaçados de dois amantes: uma francesa e um japonês, é entrecortada por imagens do que se supõe ser um documentário sobre os efeitos da bomba atômica em Hiroshima. No entanto, algumas das cenas do documentário são fictícias. As palavras ternas dos dois amantes se contrapõem todo tempo à imagem dos trágicos efeitos de Hiroshima e a descrição audível dos efeitos da bomba se contrapõe à visualização de cenas de carícias entre os amantes.

Essa transformação é o convite a uma nova pedagogia do olhar: não mais uma pedagogia da imagem-movimento, mas uma pedagogia da imagem-tempo. O olhar, antes habituado a seguir as seqüências de imagem ação, a perseguir o desenrolar de uma trama que se resolve no final, é convidado a um estado de estranhamento, de paralisia momentânea, de um não saber o que fazer ou o que seguir, e é nesse espaço que irrompe um novo espaçotempo para o pensamento e um novo exercício de subjetivação.

O modelo de subjetivação mais evidente em nossa cultura é o da individualização, ou seja, a simplificação dos diversos matizes, impulsos e possibilidades de um sujeito em uma forma única, impondo uma forma de viver e experimentar nossos corpos como uma cápsula que separa nosso eu verdadeiro do mundo exterior. Se pensarmos que a unidade do corpo é produzida por um certo exercício de domesticação do múltiplo no uno, própria do pensamento cristalizado que procede por unidades, estabilidades e linearidades (tal como o funcionamento da imagem ação), um exercício disruptor do pensamento (provocado pela imagem tempo) implicaria em um contato com multiplicidades que desconstroem essa noção de unidade, levando-nos a ser permanentemente outros. E o maior exercício de alteridade é mais do que reconhecer o direito à diferença do outro, é desejar encontros com o outro que nos arranquem da condição de permanecermos o mesmo, uma paixão por territórios desconhecidos que são um convite para uma experimentação de diferentes formas de estar no mundo. 
Suely Rolnik (1994), apoiada na esquizoanálise de Deleuze e Guattari, propõe duas formas interessantes de pensarmos a alteridade. Em uma primeira acepção mais visível, e, portanto, mais óbvia, o outro é tudo aquilo que é exterior a um eu. Ou seja, no plano do visível, captado pela percepção, o outro é tudo aquilo que está fora do invólucro que protege o meu eu, é uma unidade separável e independente com a qual me é possível criar algum tipo de relação. Mas da mesma forma que a realidade não se restringe ao visível, a subjetividade também não se restringe a um eu. Ela é "uma textura (ontológica) que vai se fazendo de fluxos e partículas que constituem nossa composição atual, conectando-se com outros fluxos e partículas com as quais estão coexistindo, somando-se e esboçando outras composições" (ROLNIK, 1994, p. 160).

A subjetividade deixa de ser uma composição estática de identidade para ser processual. A desestabilização provocada pelo encontro com diferentes fluxos "coloca a exigência de criarmos um novo corpo - em nossa existência, em nosso modo de sentir, de pensar, de agir etc. - que venha encarnar este estado inédito que se fez em nós, esta diferença que fica reverberando à espera de um corpo que a traga para o visível. E a cada vez que respondemos à exigência imposta por um destes estados - ou seja, a cada vez que encarnamos uma diferença-nos tornamos outros" (ROLNIK, 1994, p. 161). Deste ponto de vista, podemos acrescentar que o Outro não é apenas um outro eu (o estrangeiro, a mulher, o negro, o homossexual, a criança...) com o qual devo criar um exercício de vizinhança baseado na filosofia do politicamente correto. $\mathrm{O}$ Outro é tudo aquilo (humano, não humano, visível, não visível) que me arranca da pretensa estabilidade de uma identidade fixa (um modo padronizado de pensar, sentir, agir) provocando-me com um incessante convite para diferentes formas de ser-estar no mundo.

E aqui podemos voltar ao filme de Alain Resnais. O enredo do filme, se é que podemos falar de enredo em se tratando de Duras e Resnais, é um caso amoroso vivido por um japonês e uma francesa por dois dias em Hiroshima. Os dois são vistos às quatro horas da madrugada acariciando-se e conversando quando ela observa um pequeno tremor na mão de seu parceiro. Esse movimento traz à sua memória a dor que sente pelos mortos de Hiroshima, além da dor que ela mesma viveu no passado, a perda de seu antigo amante em Nevers, um jovem soldado alemão que foi morto no dia em que essa cidade foi libertada da guerra. Assim, podemos dizer que, no plano visível, o filme tematizaria um exercício de alteridade no encontro entre duas culturas: a japonesa (marcada pelos horrores da bomba de Hiroshima) e a francesa (marcada pela II Guerra e as atrocidades cometidas pelos alemães). Mas é no plano 
invisível que a temática da alteridade em Hiroshima recebe novos contornos. Hiroshima é não só um convite a pensarmos o outro, mas a sermos o outro. Diferente da postura de muitos filmes comerciais que abordam a situação de povos vitimados, por exemplo a questão judaica, levando a uma situação de piedade, e, portanto, ainda de distanciamento em relação ao outro, Hiroshima nos provoca com opsignos e sonsignos que nos levam a devir-outro.

Como ressalta Deleuze em sua análise da obra de Resnais:

Hiroshima meu amor complica ainda mais a situação. Há duas personagens, mas cada uma tem sua própria memória, alheia à outra. Não há nada mais em comum. São como duas regiões do passado, incomensuráveis, Hiroshima, Nevers. E quando o japonês recusa que a mulher entre em sua própria região ("Vi tudo...tudo - você nada viu em Hiroshima, nada...”), a mulher atrai o japonês para a sua, até certo ponto, voluntário e consentidor. Não seria para cada um uma maneira de esquecer sua própria memória, e de constituir uma memória a dois, como se agora a memória se tornasse mundo e se destacasse deles? (DELEUZE, 1990, p. 144).

É porque Resnais não está interessado em uma psicologia das personagens, se entendermos a psicologia no seu sentido de estudo de caso, traçando uma linha de continuidade e causalidade entre a vida passada de um indivíduo e sua forma de ser no presente. Resnais compreende a memória como uma memória-mundo que ultrapassa infinitamente a lembrança. Resnais não está interessado nas personagens, mas nos sentimentos que pode extrair delas fazendo-as transitar por diferentes tempos e geografias. O sentimento transborda as personagens, provocando uma tomada de consciência no espectador. O passado e o presente, Nevers e Hiroshima. É assim ainda que, segundo Deleuze, na obra de Resnais:

O mundo tornou-se memória, cérebro, superposição das idades ou dos lóbulos, mas o próprio cérebro tornou-se consciência, continuação da idades, criação ou crescimento de lóbulos sempre novos, recriação da matéria à maneira do estireno. A tela inclusive é a membrana cerebral onde se afrontam imediatamente, diretamente, o passado e o futuro, o interior e o exterior, sem distância designável, independentemente de qualquer ponto fixo (o que provoca, talvez a estranheza de Stavisky). A 
imagem não tem mais como caracteres primeiros o espaço e o movimento, mas a topologia e o tempo (DELEUZE, 1990, p. 153).

É nesse sentido que Deleuze, apoiado nas próprias declarações de Resnais, diz se tratar de um cinema cerebral. Ultrapassando uma psicologia das personagens em direção aos sentimentos, Resnais espera que estes liberem um novo exercício do pensamento. É que o cérebro, para Deleuze, longe de ser uma entidade essencialmente anatômica, é:

...uma forma consistente absoluta que se sobrevoa independentemente de qualquer dimensão suplementar, que não apela, pois a nenhuma transcendência, que só tem um único lado, qualquer que seja o número de sua dimensões, que permanece co-presente a todas as suas determinações, sem proximidade ou distanciamento, que as percorre numa velocidade infinita, sem velocidade limite, e que faz delas variações inseparáveis às quais confere uma equipotencialidade sem confusão (DELEUZE; GUATTARI, 1992, p. 270).

Já que a memória de Hiroshima e Nevers não é a memória psicológica de um japonês e de uma francesa, torna-se uma memória coletiva que transcende o vivido estritamente no plano psicológico. É justamente por ser uma memória coletiva é que surge um ponto de passagem, de translado entre as duas memórias. Um encontro que permite o imbricamento de duas memórias coletivas: Nevers e Hiroshima.

Sendo um elemento enfatizado nas pedagogias da aprendizagem, a memória sempre foi vista tradicionalmente como o elemento que permite armazenar os conteúdos de uma aprendizagem. Mas a memória em Resnais e sua pedagogia da imagem-tempo nos obriga a um novo exercício de aprendizagem. Ela nos coloca em contato com as forças que desterritorializam o pensamento. Assim, longe de pensarmos a aprendizagem como um processo que pode ser bem conduzido por um eficiente método de ensino, ela é um processo que se comunica com linhas de fuga que rompem como os resultados padronizados dos métodos de ensino. Ela se comunica não com o Mesmo, mas com o Outro do pensamento, ou seja, todos aqueles elementos estranhos que convidam a um impensável do pensamento. O contato entre as duas memórias, a de Hiroshima e de Nevers, é a possibilidade de que essas duas memórias 
possam uma desterritorializar a outra, criando uma nova história, aberta para o futuro e não para o passado. Uma memória que, longe de reviver traumaticamente os efeitos da guerra, possa recriar as geografias das relações humanas em suas infinitas novas possibilidades no encontro com o outro. É nesse sentido que pensamos o cinema como constituindo novas formas de subjetivação ao propor diferentes formas de nos relacionarmos com o nosso corpo e com o outro.

Proliferar infinitas conexões para o desejo, ensinar diferentes formas de pensar-sentir-dizer e estar no mundo, desterritorializar o pensamento, levar o corpo a devir-outro. Nisso reside talvez a maior função educativa do cinema, pois há a presença, assim como falávamos antes de uma cultura escolar, de uma cultura midiática produzida por imagens e sons que invadem nosso cotidiano e que exercem também uma função educativa. A câmera desterritorializando o olhar do espectador. Convite a uma função háptica do olhar. Nesse espaço de proximidade do olhar que já não se separa do tocar, banhados na penumbra de uma sessão de cinema somos convidados ao devaneio, a um devaneio que, longe de nos cindir do real, nos convida a habitar e a inventar outras novas realidades, a devires-outros que depois se arrastam como resíduos no caminho de volta para nossas casas. Ficam as sensações visuais e auditivas impressas em nossa memória, opsignos e sonsignos, resíduos com o poder de nos afetar e transformar as nossas vidas. Pois a ilusão não está nas imagens do cinema. Poderíamos dizer com Félix Guattari que: "A ilusão consiste em crer que existe um sujeito, um sujeito único e autônomo correspondendo a um indivíduo, quando o que está em jogo é sempre uma multidão de modos de subjetivação e de semiotização" (GUATTARI, 1980, p. 112). Assim a pedagogia da imagem-tempo no cinema é um convite a reinventarmos nossas relações com os outros e com nós mesmos, nos desprendermos de nós mesmos, liberar a vida aí onde ela está aprisionada, deviroutro, tornarmos outra coisa. 


\section{REFERÊNCIAS}

ALMEIDA, M. J. Imagens e sons: a nova cultura oral. São Paulo: Cortez, 2001.

CRUZ, P.; MAIA, L. Hiroshima meu amor. Disponível em: http://www.facom.ufba.br/ com112_2001_2/nouvellevague/hiroshima.html. Acesso em: 13 jan. 2004.

DELEUZE, G. O ato de criação. Folha de S. Paulo, 27 jun. 1999. Caderno Mais!, p. 4-5.

. Cinema 1: a imagem-movimento. São Paulo: Brasiliense, 1985.

. Cinema 2: a imagem-tempo. São Paulo: Brasiliense, 1990.

. Conversações. Rio de Janeiro: Ed. 34, 1992.

.; GUATTARI, F. O que é a filosofia? Rio de Janeiro: Ed. 34, 1992.

DURAS, M. Hiroshima mon amour: scenario et dialogues. Paris: Gallimard, 1960.

GUATTARI, F. Caosmose: um novo paradigma estético. Rio de Janeiro: Ed. 34, 1992.

GUATTARI, F. O divã do pobre. In: METZ, C. et al. Psicanálise e cinema. São Paulo: Global, 1980. p. 105-117.

ROLNIK, S. Cidadania e alteridade: o psicólogo, o homem da ética e a reinvenção da democracia. In: SPINK, M. J. P. (Org.). A cidadania em construção: uma reflexão transdisciplinar. São Paulo: Cortez, 1994. p. 157-176.

Texto recebido em 23 fev. 2005

Texto aprovado em 10 abr. 2005 